\title{
Health needs and timeliness of assessment of Victorian children entering out-of-home care: an audit of a multi-disciplinary assessment clinic
}

Type of manuscript: Original article

Karen McLean ${ }^{1,2,3}$, Keriann Little ${ }^{4,5,6}$, Harriet Hiscock ${ }^{2,3,7,8}$, Dorothy Scott $^{9}$, Sharon Goldfeld $^{1,2,3}$

\section{Addresses of institutions}

1. Policy and Equity, Murdoch Children's Research Institute, Parkville, Victoria, Australia;

2. Centre for Community Child Health, Royal Children's Hospital, Parkville, Victoria, Australia;

3. Department of Paediatrics, University of Melbourne, Parkville, Victoria, Australia.

4. Neurodevelopment and Disability, The Royal Children's Hospital, Melbourne, Victoria, Australia

5. School of Psychology, Faculty of Health, Deakin University, Geelong, Victoria, Australia

6. Barwon Child Youth \& Family, Geelong West, Victoria, Australia

7. Health Services, Murdoch Children's Research Institute, Parkville, Victoria, Australia

8. Health Services Research Unit, Royal Children's Hospital, Parkville, Victoria, Australia

9. Department of Social Work, Health Sciences, University of Melbourne

\section{Full postal, email addresses and phone number of corresponding author}

Corresponding author:

Dr Karen McLean

Address: Centre for Community Child Health, Level 2 East, Royal Children's Hospital, 50 Flemington Road, Parkville, VIC 3052, Australia.

This is the author manuscript accepted for publication and has undergone full peer review but has not been through the copyediting, typesetting, pagination and proofreading process, which may lead to differences between this version and the Version of Record. Please cite this article as doi: $10.1111 /$ jpc.14472

This article is protected by copyright. All rights reserved. 


\section{Email: karen.mclean@rch.org.au}

Phone: +61393456504

\section{Acknowledgements}

$\mathrm{KMcL}$ led the research project and the writing of the paper. KL contributed to data entry and study design. All authors contributed to planning the analysis, writing the paper and reviewing drafts.

This research is supported the Victorian Government's Operational Infrastructure Support Program. KM is supported by an Australian Government Research Training Program Scholarship PhD scholarship and Murdoch Children's Research Institute scholarship. SG is supported by Australian National Health and Medical Research Council (NHMRC) Career Development Fellowship 1082922. HH is supported by Australian National Health and Medical Research Council (NHMRC) Career Development Fellowship 1136222.

No author has a conflict of interest.

\section{Abstract}

Aim

To describe (1) the health needs identified in children attending a comprehensive health assessment at a tertiary hospital, multi-disciplinary clinic for children following entry to outof-home care and (2) timeliness of referral and assessment compared with national recommendations.

\section{Method}

Retrospective audit of all children who attended the Pathway to Good Health clinic at The Royal Children's Hospital, Melbourne from May 2013 until August 31 ${ }^{\text {st }}, 2016$. 


\section{Results:}

119 children aged 0 to 12 years attended the clinic during the audit period. 17\% (including more than $30 \%$ of 0 to 2 year olds) were not up-to-date with immunisations. $87 \%$ had physical health concerns that were addressed on the day or needed further management. Over $50 \%$ had mental health concerns identified ( $76 \%$ of 7 to 12 year olds). In children aged three to six years, $64 \%$ had behavioural problems and $77 \%$ had developmental problems identified. Only one third of children were referred to the Pathway to Good Health clinic within the national standard of 30 days post entry to care, and $24 \%$ of children attended within 3 months of entry to care.

\section{Conclusions}

Children in out-of-home care within Victoria have high rates of physical, mental and developmental health concerns, consistent with previous studies. Timeliness of attendance at the clinic was low compared with national recommendations, even within a program designed to facilitate timely health checks. This is the second and largest Australian study exploring timeliness of health checks. Further research would establish whether these results are more systemic. 


\section{What is already known on this topic:}

Children in out-of-home care have high health needs across all domains of health.

The Australian National Standards for children and young people in out-of-home care and the National Clinical Assessment Framework recommend timely health assessment following entry to out-of-home care, including an initial check within 30 days and a comprehensive assessment within 3 months.

It is challenging to provide timely health assessments for this cohort.

\section{What this paper adds:}

Victorian children in out-of-home care have high rates of health needs across all domains of health. The majority of children did not receive timely health checks that met national recommendations despite a dedicated clinic.

Immunisation rates for $0-2$ year old children in out-of-home care in Victoria were less than $70 \%$, despite several months in care.

\section{Key words}

Child

Foster care

Out-of-home care

Child health

Health assessment 


\section{Introduction}

Children living in out of home care (OOHC) are known to have higher rates of physical ${ }^{1-4}$, mental $^{5-9}$ and developmental ${ }^{4,8,10}$ health needs than the general population. This is not surprising, as the factors that have led to their placement in care are also those that are known to heighten vulnerability across all domains of health. ${ }^{11,12}$ These high rates of problems have also been shown in a small number of Australian studies from New South Wales, ${ }^{13-17}$ South Australia ${ }^{18}$ and Queensland. ${ }^{19,20}$ However there are minimal Victorian data with only 2 small older studies reporting either mental health problems (2002) from a screening clinic $(n=131),{ }^{21}$ or physical health problems and referrals made $(n=24)$ in a pilot GP program $(2008) .^{22}$

This high morbidity load is of increasing concern as the number of children and young people living in out-of-home care $(\mathrm{OOHC})$ in Victoria and Australia has been steadily rising. In Victoria alone, the number and prevalence of children and young people in $\mathrm{OOHC}$ has increased by 50\% from 6,207 (5.0 per 1,000) in 2012 to $10,312(7.5$ per 1,000) in 2017. Australia wide in 2017 there were 47,915 children and young people in Australia living in OOHC, (8.7 per 1,000 children aged 0-17 years $)^{23}$.

When children are removed from birth families, the relevant authorities take on (directly or through delegation) the responsibility for identification and management of health needs. However, case managers and carers are often not well placed to accurately identify health needs. $^{20}$

In recognition of the high health needs and the limitations of case managers and carers identifying and addressing these needs, ${ }^{20}$ peak bodies including the American Academy of Pediatrics $^{24}$ and the Royal Australasian College of Physicians ${ }^{25}$ have recommended routine, timely, systematic screening of health needs at entry to care (and regularly thereafter). Such screening is a statutory requirement in the $\mathrm{UK}^{26}$ but not in Australia, where OOHC is managed separately by each state and territory. Australia does have National Standards for $\mathrm{OOHC}^{27}$ and the National Clinical Assessment Framework for Children in Out-of-home care, ${ }^{28}$ both from federal government departments. These stipulate routine, timely and 
comprehensive health assessments including an initial health check within primary care by 30 days following entry to $\mathrm{OOHC}$, routine optometry, dental and audiology assessments, and a comprehensive health assessment by 3 months following entry to OOHC.

Despite the importance of timeliness in early identification of needs, there are few studies that report upon timeliness. Some North American studies have shown that timeliness is challenging ${ }^{29,30}$ but can be improved by addressing funding issues ${ }^{31}$ or implementing dedicated service delivery models ${ }^{32,33}$ To our knowledge, only one Australian study reports upon timeliness of assessment, in a small pilot of 24 children. ${ }^{22}$

Victoria has no state-wide approach to identifying and managing the health needs of children in OOHC. Following the release of National Clinical Assessment Framework in 2011, the Pathway to Good Health (PTGH) program was established, initially in north and west metropolitan Melbourne in 2013 and expanding regionally in 2015. This program identified General Practitioners who were willing and able to provide initial assessments within four weeks of entry to $\mathrm{OOHC}$, recommended routine optometry and dental visits within 3 months, and established dedicated multi-disciplinary clinics for comprehensive health and developmental assessments around 3 months following entry to OOHC. The clinic at the Royal Children's Hospital (RCH), Melbourne, is one of three metropolitan multi-disciplinary clinics. This study aimed to describe the health needs of the children seen in the PTGH multidisciplinary clinic at $\mathrm{RCH}$ and compare the timeliness of their comprehensive health assessment and GP visit to national recommendations.

\section{Methods}

\section{Setting}

This study is a retrospective audit of the health notes and Health Management Plans for the first consecutive 119 patients to attend the PTGH clinic at RCH from its commencement in May 2013 until August $31^{\text {st }}, 2016$. The PTGH Clinic at RCH is funded by the Victorian Department of Health and Human Services to provide comprehensive health assessments for children aged $0-12$ years following entry to OOHC in the north or west metropolitan 
Melbourne area. The Child Protection case manager initiates the process by facilitating a GP visit, and referral is then made to the clinic.

The child attends clinic once, accompanied by one or more of the following adults: their foster or kinship carer, departmental case manager or case worker from a foster care agency. Other attendees may include other foster family members, siblings in the same placement as the child, biological parents or other birth family members. Children are assessed by a paediatrician and a psychologist, and those aged from two to seven years (inclusive) are also assessed by a speech pathologist. The clinicians take two to three hours to assess the child, including taking a standardised history from the child and any accompanying adults (using a checklist), observation of the child and physical examination. The speech and language assessment may include standardised tests. A single health management plan is co-written by the clinicians, and sent to the case manager, referring GP and health professionals caring for the child. This plan outlines identified health needs and recommended next steps for treatment or further assessment.

\section{Data collection and analysis}

KMcL entered de-identified data included demographic information (age, gender, placement information (where possible), date of entry to OOHC and previous episodes of OOHC. If the full date of entry was not available, a conservative estimate was used (for example, if only a month and year were recorded, the last date of the month was used). To validate the accuracy of the data entry KL independently entered data for $10 \%$ of the cohort. Where agreement between researchers was less than $90 \%$ for any variable, both researchers jointly reviewed all patients.

Physical health problems and concerns about development, behaviour (e.g. aggressive, difficult to manage or unusual behaviours), schooling or mental health (e.g. abnormal attachment, trauma-related symptoms) were noted if they required either attention during the assessment or a recommendation in the health management plan. Recommendations and referrals were recorded, and if they had already been initiated by someone else this was also noted. 
Descriptive statistics were calculated using Stata, (Stata v15.1, released 2017, College Station, Texas, USA).

Ethical approval for the audit was granted by the Royal Children's Hospital Human Research Ethics Committee (36258A).

\section{Results}

119 children were seen during the study period. Demographics of the cohort are shown in Table 1. While two thirds of the cohort were in their first placement, more than $20 \%$ had changed placement at least once. The median time to GP referral from entry to OOHC was 57 days (ranging from $1-2359$ days); it was shorter for $0-2$ year old children (48 days) than 7 12 year old children (88 days). The median time from GP referral to clinic visit was 70 days. Overall, the median time from entry to $\mathrm{OOHC}$ to comprehensive health assessment in the clinic was 163 days (range 35 - 2472 days) - varying from a median of 117 days for the $0-2$ year old children to 212 days for the $7-12$ year old children. Table 2 shows the proportion meeting the national recommendations for timeliness of visits.

Figure 1 shows the proportion of children who had dental, hearing or vision assessments before attending the clinic. The highest rates of assessments were dental reviews in children aged $7-12$ years, where over half of children had already seen the dentist.

Table 3 shows the immunisation status at the time of the clinic visit. For some children this was not evident, and these were classified as "not known". Over 30\% of $0-2$ year old children who attended were not up-to-date with their immunisations as per the National Immunisation Schedule.

Figure 2 shows the proportion identified with health concerns in each domain of health within each age group and the entire cohort. Only $13 \%$ of children had no physical health problems discussed or identified in their assessment. Many physical health concerns were typical of childhood health problems: 16 children (14\%) had asthma and 29 (24\%) had eczema. Abdominal pain, constipation and/or encopresis were found in 29 children (24\%). Sleep problems, including symptoms of obstructive sleep apnoea, parasomnias and behavioural 
sleep challenges, were found in 17 children (14\%). Seven children (6\%) were found to have previously unidentified heart murmurs, and three were found to have previously attended our hospital for follow-up of cardiac or renal abnormalities and then failed to attend ongoing follow-up, unknown by either carers or case managers.

Mental health concerns were identified in the majority of children aged over 3 years and up to $76 \%$ of 7 to 12 year old children. These often related to experiences of trauma and internalising symptoms being identified. Almost half of all children had challenging behaviours in either the home or school setting, from excessive tantrums through to aggression. Developmental concerns were most prevalent in the $3-6$ year old age group; speech and language concerns were the most frequently identified. Two thirds of children aged 7 to 12 years had school-related concerns, usually academic and/or peer related.

Table 4 reports the frequency of new recommendations made in health management plans at the end of assessment; other treatment or referrals that had already been initiated were not included. Around half of all children were found to need ongoing paediatric care because of the nature and/or extent of concerns. 21 children (18\%) were referred to another medical or surgical specialist specifically as a result of their clinic attendance. Close to half of all children had recommendations relating to their mental health (for further assessment and/or therapy), including $77 \%$ of $7-12$ year old children. Over half of $3-6$ year old children needed audiology assessment, which often followed identification of speech and language concerns in children who had not yet had their hearing tested; $62 \%$ of this age group had speech therapy recommended.

\section{Discussion}

This study describes the health needs identified at a comprehensive multi-disciplinary assessment clinic for Victorian children in OOHC. Health needs and recommendations for further health service use were highly prevalent across all domains of health, consistent with previous interstate and international studies. Timeliness of attendance at the clinic was poor when compared to national recommendations. 
Physical health needs were the most prevalent. While some health problems appear to be comparable with parent-reported rates for all Australian children (e.g. asthma, sleep problems), ${ }^{34}$ others were more prevalent among the study cohort than Australian children, ${ }^{34}$ although possibly in line with some global general prevalence rates (e.g. eczema, abdominal pain, constipation and soiling). ${ }^{35}$ The overall high prevalence of physical health problems is in line with other Australian studies of children in OOHC. ${ }^{14,19,20}$ Some of the somatic symptoms identified in clinic may have had an underlying mental health aetiology, in line with previous studies that have shown increased somatic symptoms in children with exposure to trauma. ${ }^{36}$

While routine dental, vision and audiology (hearing) checks are included in the national guidelines, audiology was not included within the PTGH program as a routine requirement. It is therefore unsurprising that fewer children had audiology compared with dental and vision checks before attending the clinic. However, it is concerning that only $52 \%$ of children aged at least three years had attended a dentist, especially when considering the poor timeliness in attendance.

It was concerning that immunisation rates were low, despite the comprehensive health assessment following at least one contact with the primary health care system for an initial health check. This was true particularly amongst the 0 to 2 year old children, where at best $69 \%$ were fully immunised as per the National Immunisation Schedule by the time of their clinic appointment - despite $66 \%$ having been in OOHC for more than three months.

While physical health problems were most prevalent, mental health, developmental and behavioural concerns were also prevalent. These domains of health are known to contribute to placement breakdown for children in $\mathrm{OOHC}^{37-40}$ and placement breakdown appears to impede the provision of health care. ${ }^{41}$ At least $20 \%$ of our cohort had changed placement at least once prior to their comprehensive health assessment, but total numbers were too small to explore the relationship between mental health concerns, placement breakdown and timeliness of assessment. 
It is unsurprising that mental health and developmental concerns generated the most recommendations for further assessment or treatment. The high rates of referral for mental health care, speech therapy and ongoing paediatric care are also similar to interstate Australian studies ${ }^{14,15,19,20,22}$ and add to the evidence that children in OOHC warrant both careful and timely identification of health needs and access to services.

Based on models elsewhere that have been shown to facilitate health checks, ${ }^{32,33}$ the PTGH program was designed to facilitate timely health assessments for children following entry to OOHC. This audit shows that an initial health check by 1 month may have only been achieved in about one third of children and a comprehensive health check by 3 months was completed in about one quarter. However, it is not clear whether the GP visit that generated the referral was the first GP visit for these children; it is possible that more children had a prompt initial health check and were then referred to clinic at a subsequent visit. However, the low figures for timely comprehensive health checks suggest that timeliness of identification of health needs of children entering $\mathrm{OOHC}$ is poor.

${ }^{40,41}$ Despite data from only one clinic, this study is the largest Victorian and one of the largest Australian studies of health needs in children in OOHC across all domains of health. This is also the second and largest Australian study to report on timeliness of attendance in a model designed to provide timely assessment of health needs upon entry to OOHC.

There are considerable limitations to this study worth noting. The sample in this cohort is limited to those referred for a comprehensive health assessment in one PTGH clinic. Our sample is broadly similar to children in OOHC in Victoria, with $49 \%$ boys and $58 \%$ in kinship care compared to $52 \%$ and $49 \%$ of Victorian children in OOHC in 2016-17 respectively. ${ }^{23}$ However, only $14 \%$ of our cohort were Aboriginal and/or Torres Strait Islander children (compared to $20 \%$ of Victorian children in $\mathrm{OOHC}$ ).

The findings regarding timeliness are limited by the lack of information about GP visits and initial health assessments outside of the visit that generated the referral to our clinic. The generalisability of our findings is limited by the absence of information about children who were not referred to the clinic. We cannot determine from this study the overall rates and 
timeliness of health checks within Victoria, nor be confident about whether the sample seen in clinic was representative of all children in OOHC with respect to health needs. Further research is needed to determine the true timeliness of health assessment for all children in $\mathrm{OOHC}$ and to explore barriers and enablers to health service access.

\section{Conclusion}

Children in $\mathrm{OOHC}$ within Victoria had high rates of physical, mental and developmental health concerns, adding to previous Australian and international research. Immunisation rates were low, particularly for the youngest children (aged $0-2$ years). Timeliness of attendance at the dedicated multidisciplinary assessment clinic for a comprehensive assessment of health needs was poor compared with national recommendations, even within a broader program designed to facilitate timely health checks. Timely identification and management of health needs for children in $\mathrm{OOHC}$ continues to be challenging to deliver. 


\section{References}

1. Deutsch SA, Fortin K. Physical Health Problems and Barriers to Optimal Health Care Among Children in Foster Care. Curr Probl Pediatr Adolesc Health Care. 2015; 45: 286-91.

2. Dubowitz H, Feigelman S, Zuravin S, Tepper V, Davidson N, Lichenstein R. The physical health of children in kinship care. Am J Dis Child. 1992; 146: 603-10.

3. Flaherty EG, Weiss H. Medical evaluation of abused and neglected children. Am J Dis Child. 1990; 144: 330-4.

4. Leslie LK, Gordon JN, Meneken L, Premji K, Michelmore KL, Ganger W. The physical, developmental, and mental health needs of young children in child welfare by initial placement type. J Dev Behav Pediatr. 2005; 26: 177-85.

5. Teggart T, Menary J. An Investigation of the Mental Health Needs of Children Looked After by Craigavon and Banbridge Health and Social Services Trust. Child Care in Practice. 2005; 11: 39-49.

6. Williams J, Jackson S, Maddocks A, Cheung W, Love A, Hutchings H. Case-control study of the health of those looked after by local authorities. Arch Dis Child. 2001; 85: 280-5.

7. Egelund T, Lausten M. Prevalence of mental health problems among children placed in out-of-home care in Denmark. Child \& Family Social Work. 2009; 14: 156-65.

8. Deutsch SA, Lynch A, Zlotnik S, Matone M, Kreider A, Noonan K. Mental Health, Behavioral and Developmental Issues for Youth in Foster Care. Current Problems in Pediatric and Adolescent Health Care. 2015; 45: 292-7.

9. Conn A-M, Szilagyi MA, Alpert-Gillis L, Baldwin CD, Jee SH. Mental health problems that mediate treatment utilization among children in foster care. Journal of Child and Family Studies. 2016; 25: 969-78.

10. Ford T, Vostanis P, Meltzer H, Goodman R. Psychiatric disorder among British children looked after by local authorities: comparison with children living in private households. Br J Psychiatry. 2007; 190: 319-25. 
11. Marmot M. Social determinants of health inequalities. The Lancet. 2005; 365: 1099104.

12. Felitti VJ, Anda RF, Nordenberg D, Williamson DF, Spitz AM, Edwards V, et al. Relationship of childhood abuse and household dysfunction to many of the leading causes of death in adults. The Adverse Childhood Experiences (ACE) Study. Am J Prev Med. 1998; 14: 245-58.

13. Chambers MF, Saunders AM, New BD, Williams CL, Stachurska A. Assessment of children coming into care: processes, pitfalls and partnerships. Clin Child Psychology Psychiatry. 2010; 15: 511-27.

14. Nathanson D, Tzioumi D. Health needs of Australian children living in out-of-home care. J Paediatr Child Health. 2007; 43: 695-9.

15. Raman S, Reynolds S, Khan R. Addressing the well-being of Aboriginal children in out-of-home care: Are we there yet? J Paediatr Child Health. 2011; 47: 806-11.

16. Raman S, Sahu S. Health, Developmental and Support Needs of Vulnerable Children - Comparing Children in Foster Care and Children in Need. Child Abuse Review. 2014; 23: 415-25.

17. Tarren-Sweeney M, Hazell P. Mental health of children in foster and kinship care in New South Wales, Australia. J Paediatr Child Health. 2006; 42: 89-97.

18. Sawyer MG, Carbone JA, Searle AK, Robinson P. The mental health and wellbeing of children and adolescents in home-based foster care. Med J Aust. 2007; 186: 181-4.

19. Arora N, Kaltner M, Williams J. Health needs of regional Australian children in outof-home care. J Paediatr Child Health. 2014; 50: 782-6.

20. Kaltner M, Rissel K. Health of Australian children in out-of-home care: needs and carer recognition. J Paediatr Child Health. 2011; 47: 122-6. 
21. Milburn NL, Lynch M, Jackson J. Early identification of mental health needs for children in care: a therapeutic assessment programme for statutory clients of child protection. Clin Child Psychology Psychiatry. 2008; 13: 31-47.

22. Tremellen S, Van Doorn H. General practice: role and experience as providers of comprehensive health assessment for children and young people in out-of-home care. Developing Practice. 2012 30:41-8.

23. AIHW. Child protection Australia 2016-17. Australian Institute of Health and Welfare; 2018.

24. Canadian Paediatric Society. Special considerations for the health supervision of children and youth in foster care. Paediatrics and Child Health. 2008; 13: 129-36.

25. Royal Australasian College of Physicians. Health of children in "out-of-home"care. Sydney: RACP; 2006.

26. Department for Education and Department of Health. Promoting the health and wellbeing of looked-after children: Statutory guidance for local authorities, clinical commissioning groups and NHS England. England 2015.

27. Department of Families Housing, Community Services and Indigenous Affairs together with the National Framework Implementation Working Group. An outline of National Standards for Out - of- home Care. Australia, 2011.

28. Child Health and Wellbeing Subcommittee, Australian Population Health Developmental Principal Committee. National Clinical Assessment Framework for Children and Young People in Out-of-Home Care (OOHC). Australia, 2011.

29. Goldade R, Tortorelli C. P-KIC -pediatrics for kids in care. Paediatrics and Child Health. 2010; 15: 10A.

30. Knight EK, McDuffie MJ, Gifford K, Zorc C. Health Service Utilization of Children in Delaware Foster Care, 2013-2014. Del Med J. 2016; 88: 46-52. 
31. Day A, Curtis A, Paul R, Allotey PA, Crosby S. Timely Health Service Utilization of Older Foster Youth by Insurance Type. J Adolesc Health. 2016; 58: 17-23.

32. Risley-Curtiss C, Stites B. Improving healthcare for children entering foster care. Child Welfare. 2007; 86: 123-44.

33. Jee S, Szilagyi M, Blatt S, Meguid V, Auinger P, Szilagyi P. Timely identification of mental health problems in two foster care medical homes. Children and Youth Services Review. 2010; 32: 685-90.

34. Liu T, Lingam R, Lycett K et al. Parent-reported prevalence and persistence of 19 common child health conditions. Arch Dis Child. 2018; 108: 548-56.

35. Waterham M, Kaufman J, Gibb S. Childhood constipation. Aust Fam Physician. 2017; 46: 908-12.

36. Kugler B, Bloom M, Kaercher L, Truax T, Storch E. Somatic Symptoms in Traumatized Children and Adolescents. Child Psychiatry Hum Dev. 2012; 43: 661-73.

37. Park JM, Ryan JP. Placement and permanency outcomes for children in out-of-home care by prior inpatient mental health treatment. Research on Social Work Practice. 2009; 19: $42-51$.

38. Sallnas M, Vinnerljung B, Kyhle WP, Sallnäs M, Westermark P. Breakdown of teenage placements in Swedish foster and residential care. Child and family social work 2004; 9: 141-52

39. Brown JD, Bednar LM. Foster parent perceptions of placement breakdown. Children and Youth Services Review. 2006; 28: 1497-511.

40. Koh E, Rolock N, Cross TP, Eblen-Manning J. What explains instability in foster care? Comparison of a matched sample of children with stable and unstable placements. Children \& Youth Services Review. 2014; 37: 36-45. 
41. Kerns SEU, Pullmann MD, Putnam B, Buher A, Holland S, Berliner L, et al. Child welfare and mental health: Facilitators of and barriers to connecting children and youths in out-of-home care with effective mental health treatment. Children \& Youth Services Review. 2014; 46: 315-24. 
Table 1: Demographics of study sample.

\begin{tabular}{|c|c|}
\hline Total & $\mathbf{N}(\%)$ \\
\hline \multicolumn{2}{|l|}{ Sex } \\
\hline Male & $58(48.7)$ \\
\hline Female & $61(51.3)$ \\
\hline \multicolumn{2}{|l|}{ Age (years) } \\
\hline$<1$ & $9(7.6)$ \\
\hline $1-2$ & $26(21.8)$ \\
\hline $3-6$ & $39(32.8)$ \\
\hline $7-12$ & $45(37.8)$ \\
\hline Aboriginal and/or Torres Strait Islander children & $17(14.3)$ \\
\hline \multicolumn{2}{|l|}{ Care Type } \\
\hline Foster care & $43(36.1)$ \\
\hline Kinship care & $69(58.0)$ \\
\hline Residential care & $1(0.8)$ \\
\hline Other* & $6(5.0)$ \\
\hline \multicolumn{2}{|l|}{ Number of placements } \\
\hline 0 & $2(1.7)$ \\
\hline 1 & 79 (66.4) \\
\hline 2 & $16(13.5)$ \\
\hline 3 & $3(2.5)$ \\
\hline 4 or more & $6(5.0)$ \\
\hline Unknown & $13(10.9)$ \\
\hline
\end{tabular}

*Other included reunified, never in OOHC (brought as a sibling) and other care arrangement 
Table 2: Comparison with the National Clinical Assessment Framework

\begin{tabular}{llc}
\hline Recommendation & Age & $\begin{array}{c}\text { Number (\%) meeting the } \\
\text { recommendation }\end{array}$ \\
\hline $\begin{array}{l}\text { GP visit by 30 days } \\
\text { generating referral to PTGH }\end{array}$ & 0 - 2 year olds & $10(28.5)$ \\
clinic & 7 - 12 year olds & $15(38.5)$ \\
& All & $14(31.1)$ \\
& 0 - 2 year olds & $39(32.8)$ \\
\hline PTGH comprehensive & 3 - 6 year olds & $12(34.2)$ \\
days $)$ & 7 - 12 year olds & $10(25.6)$ \\
& All & $6(13.3)$ \\
& & $28(23.5)$ \\
\hline
\end{tabular}

Table 3: Immunisation status at time of clinic visit

\begin{tabular}{|c|c|c|c|c|}
\hline Immunisation status & $\begin{array}{l}\text { o - } 2 \text { years } \\
(\mathrm{n}(\%))\end{array}$ & $\begin{array}{l}3 \text { - } 6 \text { years } \\
(n(\%))\end{array}$ & $\begin{array}{l}7 \text { - } 12 \text { years } \\
(n(\%))\end{array}$ & Total $(\mathrm{n}(\%))$ \\
\hline Up-to-date & $22(62.9)$ & $32(82.1)$ & $34(75.6)$ & $88(74.9)$ \\
\hline Not up-to-date & $11(31.4)$ & $5(12.8)$ & $4(8.9)$ & $20(16.8)$ \\
\hline Unknown & $2(5.7)$ & $2(5.1)$ & $7(15.6)$ & $11(9.2)$ \\
\hline
\end{tabular}


Table 4: Recommendations made after clinic assessment

\begin{tabular}{|c|c|c|c|c|}
\hline Recommendation & $\begin{array}{c}0 \text { - } 2 \text { year olds } \\
(\mathrm{n}(\%)) \\
\end{array}$ & $\begin{array}{c}3 \text { - } 6 \text { year olds } \\
(\mathrm{n}(\%)) \\
\end{array}$ & $\begin{array}{c}7-12 \text { year olds } \\
(\mathbf{n}(\%))\end{array}$ & $\begin{array}{c}\text { Total } \\
(\mathbf{n}(\%))\end{array}$ \\
\hline Referral to paediatrician & $11(31.4)$ & $19(54.3)$ & $24(53.3)$ & $54(45.4)$ \\
\hline $\begin{array}{l}\text { Other new subspecialty } \\
\text { referral }\end{array}$ & $8(22.9)$ & $7(17.9)$ & $6(13.3)$ & $21(17.6)$ \\
\hline Dentist & $4(11.4)$ & $13(33.3)$ & $17(37.8)$ & $34(28.6)$ \\
\hline Audiology & $11(31.4)$ & $21(53.8)$ & $14(31.1)$ & $46(38.7)$ \\
\hline Vision & $5(14.3)$ & $12(30.8)$ & $15(33.3)$ & $32(26.9)$ \\
\hline Mental health referral & $3(8.6)$ & $20(51.3)$ & $32(71.1)$ & $55(46.2)$ \\
\hline Speech therapy & $4(11.4)$ & $18(46.2)$ & $8(17.3)$ & $30(25.2)$ \\
\hline
\end{tabular}




\section{Figure Legends}

Figure 1: Proportion of children who had completed dental, hearing and vision assessments before attending clinic.

Figure 2: Percentage of children with concerns by age and health domain 
Figure 1: Proportion of children who had completed dental, hearing and vision assessments before attending clinic.

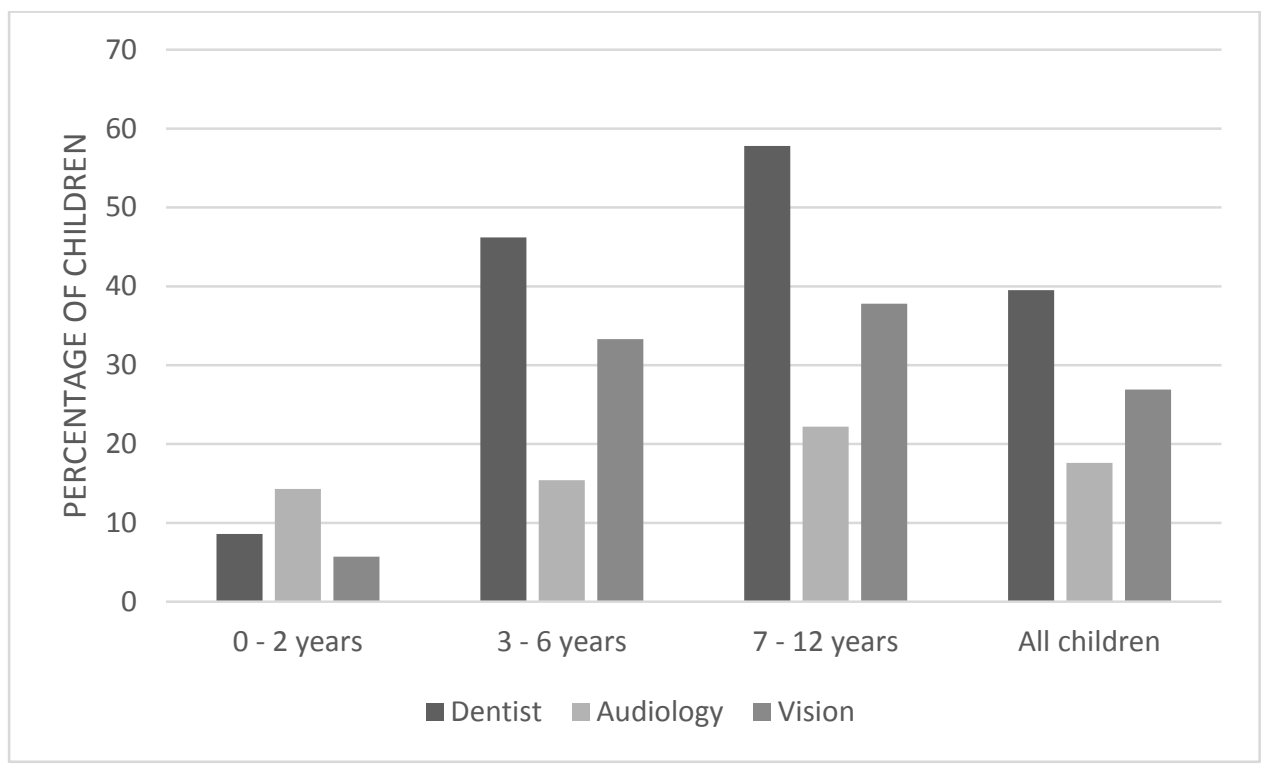

This article is protected by copyright. All rights reserved. 
Figure 2: Percentage of children with concerns by age and health domain

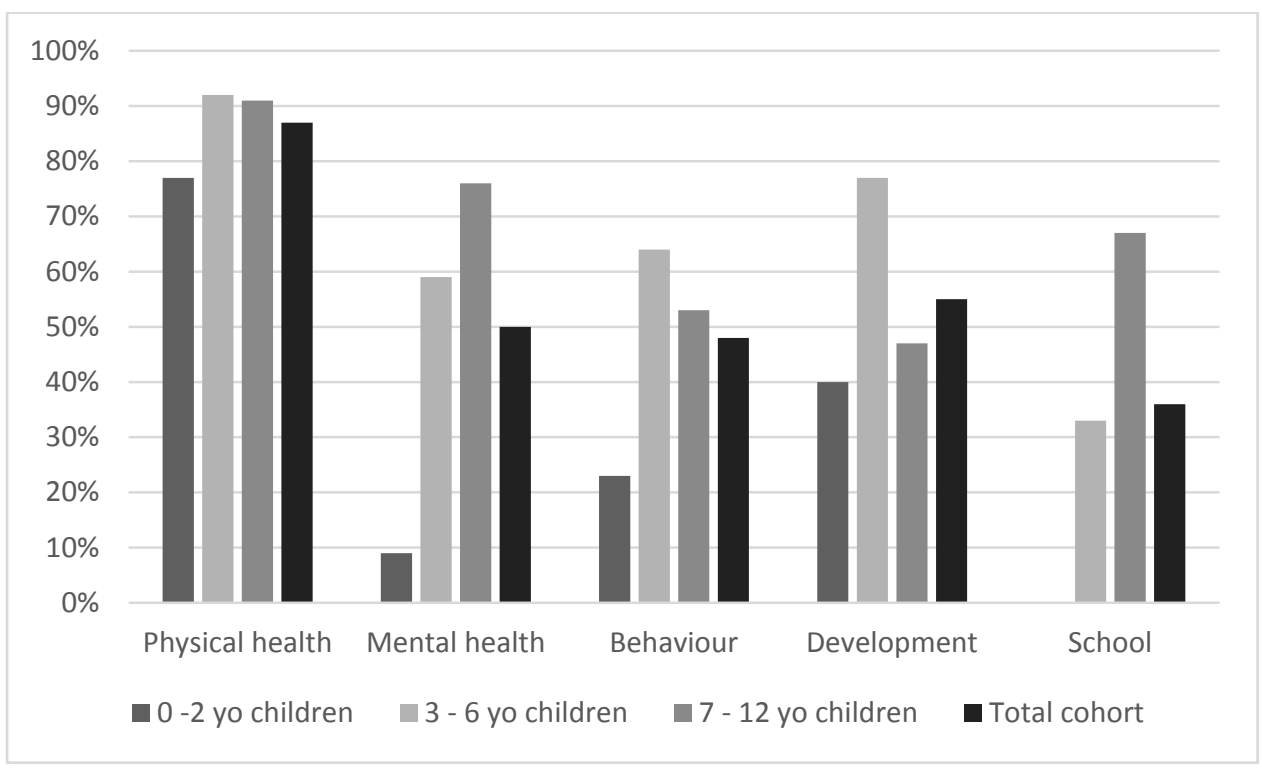

This article is protected by copyright. All rights reserved. 
Health needs and timeliness of assessment of Victorian children entering out-of-home care: an audit of a multi-disciplinary assessment clinic

Type of manuscript: Original article

Karen McLean ${ }^{1,2,3}$, Keriann Little ${ }^{4,5,6}$, Harriet Hiscock ${ }^{2,3,7,8}$, Dorothy Scott $^{9}$, Sharon Goldfeld $^{1,2,3}$

\section{Addresses of institutions}

1. Policy and Equity, Murdoch Children's Research Institute, Parkville, Victoria, Australia;

2. Centre for Community Child Health, Royal Children's Hospital, Parkville, Victoria, Australia;

3. Department of Paediatrics, University of Melbourne, Parkville, Victoria, Australia.

4. Neurodevelopment and Disability, The Royal Children's Hospital, Melbourne, Victoria, Australia

5. School of Psychology, Faculty of Health, Deakin University, Geelong, Victoria, Australia

6. Barwon Child Youth \& Family, Geelong West, Victoria, Australia

7. Health Services, Murdoch Children's Research Institute, Parkville, Victoria, Australia

8. Health Services Research Unit, Royal Children's Hospital, Parkville, Victoria, Australia

9. Department of Social Work, Health Sciences, University of Melbourne

\section{Full postal, email addresses and phone number of corresponding author}

Corresponding author:

Dr Karen McLean

Address: Centre for Community Child Health, Level 2 East, Royal Children's Hospital, 50 Flemington Road, Parkville, VIC 3052, Australia.

Email: karen.mclean@,rch.org.au

Phone: +61 393456504 


\section{Acknowledgements}

$\mathrm{KMcL}$ led the research project and the writing of the paper. KL contributed to data entry and study design. All authors contributed to planning the analysis, writing the paper and reviewing drafts.

This research is supported the Victorian Government's Operational Infrastructure Support Program. KM is supported by an Australian Government Research Training Program Scholarship PhD scholarship and Murdoch Children's Research Institute scholarship. SG is supported by Australian National Health and Medical Research Council (NHMRC) Career Development Fellowship 1082922. HH is supported by Australian National Health and Medical Research Council (NHMRC) Career Development Fellowship 1136222.

No author has a conflict of interest. 


\section{University Library}

\section{- M M I N E R VA A gateway to Melbourne's research publications}

Minerva Access is the Institutional Repository of The University of Melbourne

\section{Author/s:}

McLean, K;Little, K;Hiscock, H;Scott, D;Goldfeld, S

Title:

Health needs and timeliness of assessment of Victorian children entering out-of-home care: An audit of a multidisciplinary assessment clinic

\section{Date:}

2019-12-01

\section{Citation:}

McLean, K., Little, K., Hiscock, H., Scott, D. \& Goldfeld, S. (2019). Health needs and timeliness of assessment of Victorian children entering out-of-home care: An audit of a multidisciplinary assessment clinic. JOURNAL OF PAEDIATRICS AND CHILD HEALTH, 55 (12), pp.1470-1475. https://doi.org/10.1111/jpc.14472.

Persistent Link:

http://hdl.handle.net/11343/285693 